\title{
Feasibility Study of Commercial Markets for New Sample Acquisition Devices
}

\author{
Collin Brady ${ }^{1}$, Jim Coyne ${ }^{2}$, Sven G. Bilén ${ }^{3}$, Liz Kisenwether ${ }^{4}$, Garry Miller ${ }^{5}$ \\ The Pennsylvania State University, University Park, PA 16802, USA \\ and \\ Robert P. Mueller ${ }^{6}$, \\ National Aeronautics \& Space Administration (NASA), Kennedy Space Center, 32899, FL, USA \\ and \\ Kris Zacny ${ }^{7}$ \\ Honeybee Robotics, Pasadena, CA 91103, USA
}

\begin{abstract}
The NASA Exploration Systems Mission Directorate (ESMD) and Penn State technology commercialization project was designed to assist in the maturation of a NASA SBIR Phase III technology. The project was funded by NASA's ESMD Education group with oversight from the Surface Systems Office at NASA Kennedy Space Center in the Engineering Directorate. Two Penn State engineering student interns managed the project with support from Honeybee Robotics and NASA Kennedy Space Center. The objective was to find an opportunity to integrate SBIR-developed Regolith Extractor and Sampling Technology as the payload for the future Lunar Lander or Rover missions. The team was able to identify two potential Google Lunar X Prize organizations with considerable interest in utilizing regolith acquisition and transfer technology.
\end{abstract}

\section{Introduction}

NASA is currently repositioning itself to align mission objectives and infrastructure with the vision of President Obama's administration'. The strategic realignment will result in increased reliance and collaboration with private industry, including large systems integrators and small innovative research companies. The six-billion dollar budget increase over the next five years will prioritize innovation and drive space and Earth climate research. The Augustine report indicated there was insufficient funding to support the Constellation program while continuing to sustain other agency objectives, such as the International Space Station (ISS). A strong recommendation was made to support the development of disruptive technologies that would enable exploration beyond low earth orbit (LEO) and ensure NASA maintains its leadership role in space.

The Agency's new focus on research, along with the increase in available funding for such projects, will bring about a large increase and new emphasis on autonomous and unmanned exploration into deeper space than has been previously attempted. This new emphasis on research and exploration will lead to not only deep space probes and

1 NASA Intern, 111 Maryland Avenue, Vandergrift, PA 15690, AIAA Student Member.

2 NASA Intern, AIAA Student Member.

3 Associate Professor, Engineering Design, Electrical Engineering, and Aerospace Engineering, 213 Hammond Bldg., AIAA Associate Fellow.

${ }^{4}$ Assistant Professor, Engineering Design.

5 Program Manager, Technology \& Product Commercialization, NASA Langley TecFusion Team.

${ }^{6}$ Chief, Surface Systems Office, NE-S, NASA KSC, FL 32899

7 Director, Drilling and Excavation Systems, 398 W Washington Blvd., Suite 200, Pasadena, CA 91103, AIAA Member. 
spacecraft, but also to a new generation of autonomous ground vehicles and rovers. This will be important as NASA attempts to explore and analyze not just Earth's moon and Mars, but also nearby comets and other planets and moons within our solar system. Both autonomous and remotely piloted ground rovers will be a large part of NASA's future scientific research plans. With the Agency's new emphasis on partnering and coordinating efforts with private industry, private companies who specialize in these types of mechanisms are in a powerful position to contribute to the future of NASA's scientific research.

A near term reduction in human space exploration will also accelerate an emphasis in advanced robotics for increasingly complex unmanned missions. NASA again is in a position to be a leader in collaborating with industry and academia to lead in the development of game-changing technologies. These technological advancements will be integrated into applications here on Earth, in much the same fashion that the Apollo program was an enabler to benefit society.

Work which the NASA Kennedy Space Center and Honeybee Robotics has conducted with the regolith excavator and conveyor technology is an example of teaming between the agency and the private sector to create a mission critical space technology. Funding through the Small Business Innovation Research (SBIR) program, has led to the successful demonstration of the technology in a simulated environment. The ESMD project team has been working on a task to identify a path to integrate the technology into a lunar lander or rover and prove the autonomous value on the surface of the moon. Several Google Lunar X prize candidates appear to be a potential match and discussions are underway to create a formal project ${ }^{2}$. Initial contacts have also been made with the Caterpillar Corporation as the team believes the combination of large and small private sector organizations is an important element of the technology maturation process.

As NASA increases collaborative work with private sector organizations, greater emphasis has been placed on bringing together small innovators with larger systems or sub-system integrators. Identifying, developing and integrating highly innovative technologies will be a critical success factor for a successful unmanned NASA space program

Having reliable robotic technology to extract and sample regolith from the Moon, Mars, and other deep space destination is a critical success factor for future missions. The production of oxygen from regolith would reduce mass of fuel and other consumables which must be transported into space ${ }^{3}$. The objective of this project was to determine if there might be an opportunity to integrate Honeybee Robotics SBIR developed Regolith Extractor and Sampling Technology, which is currently a phase-III NASA SBIR technology, as the payload on a future commercial lunar lander or rover mission. A prototype of the Honeybee Robotics technology was successfully demonstrated during the field tests in February of 2010 in Hawaii. There is a real challenge for this, and other Technology Readiness Level (TRL)-5 technologies, in identifying potential collaborators, partners and funding streams to further advance mid-range TRL technologies.

The project was funded by NASA's ESMD Education group with oversight by the Surface Systems Office at NASA Kennedy Space Center in the Engineering Directorate. Two Penn State University Aerospace Engineering students, with minors in Engineering Entrepreneurship, managed the project with support from Honeybee Robotics and Kennedy Space Center.

The intern team was able to identify two potential Google Lunar X Prize organizations with considerable interest in utilizing Honeybee Robotics technology as a payload in their lunar landers. The field of 20 was reduced to those organizations that

a) were interested considering payloads from outside their organizations;

b) were responsive to our inquires and those of the Google X Prize staff; and

c) met unique payload specifications.

The evaluated specifications included mass, volume, energy, and other physical requirements.

\section{Commercialization}

\section{A. Scope of Work}

The goal of the project was to enable Penn State Aerospace Engineering interns to assist in the maturing of Honeybee Robotics" NASA SBIR Phase III technology: "Pneumatic Transfer Regolith Feed System for the Carbothermal Oxygen Production System4". A key component to implementing a technology maturation process was to understand the needs and desires of the technology integrator. Another critical success factor was an assessment of the state of the technology to be integrated into a finished product or service. The project required an understanding of the Google Lunar X Prize partner requirements, the state of the Honeybee Robotics technology, and the creation of a gap analysis to determine the necessary steps to meet the target requirements. A paper was 
prepared to integrate the regolith excavation technology as a mission load for a Google's X prize partner. The project period was from 8 February to 21 May 2010.

\section{B. Need for the Regolith Excavation Technology}

The production of oxygen from regolith on the Moon is an attractive technology option since it can reduce the total mass of consumables that must be taken to the Moon from the Earth. If the mass of oxygen produced and consumed on the Moon significantly exceeds the mass of the equipment that is transported from Earth to the Moon in order to make this possible, then there will be a benefit to the overall architecture. One of the goals of In Situ Resource Utilization (ISRU) on the Moon is to produce oxygen from the lunar regolith, which is present in the form of ilmenite (FeTiO3) and other compounds $s^{5,6}$. One challenge for a production system is to reliably acquire the regolith with an excavator hauler mobility platform and then introduce it into the reactor inlet tube above the reactor.

\section{Pneumatic Technology}

Lunar regolith, because of its nature, is highly abrasive. The Apollo astronauts' spacesuit seals and joints began to fail after only 1-2 days on the surface of the Moon. Lunar excavators having a life requirement of years will have to deal with abrasive environment by encapsulating/sealing moving surfaces such as bushings and bearings. However, seals that will protect moving systems will eventually wear out, too. Thus, an approach that completely eliminates moving surfaces would be ideal. An example of a possible technology is a pneumatic approach.

\section{A. Principles of the Pneumatic Regolith Excavation Technology}

The pneumatic sample acquisition can be used to acquire regolith in situ and deliver it directly to a science instrument, ISRU plant, or sample return capsule without the need of moving robotic arms. The system can be integrated with a lander (e.g., on precursor missions) or a rover (e.g., mining system).

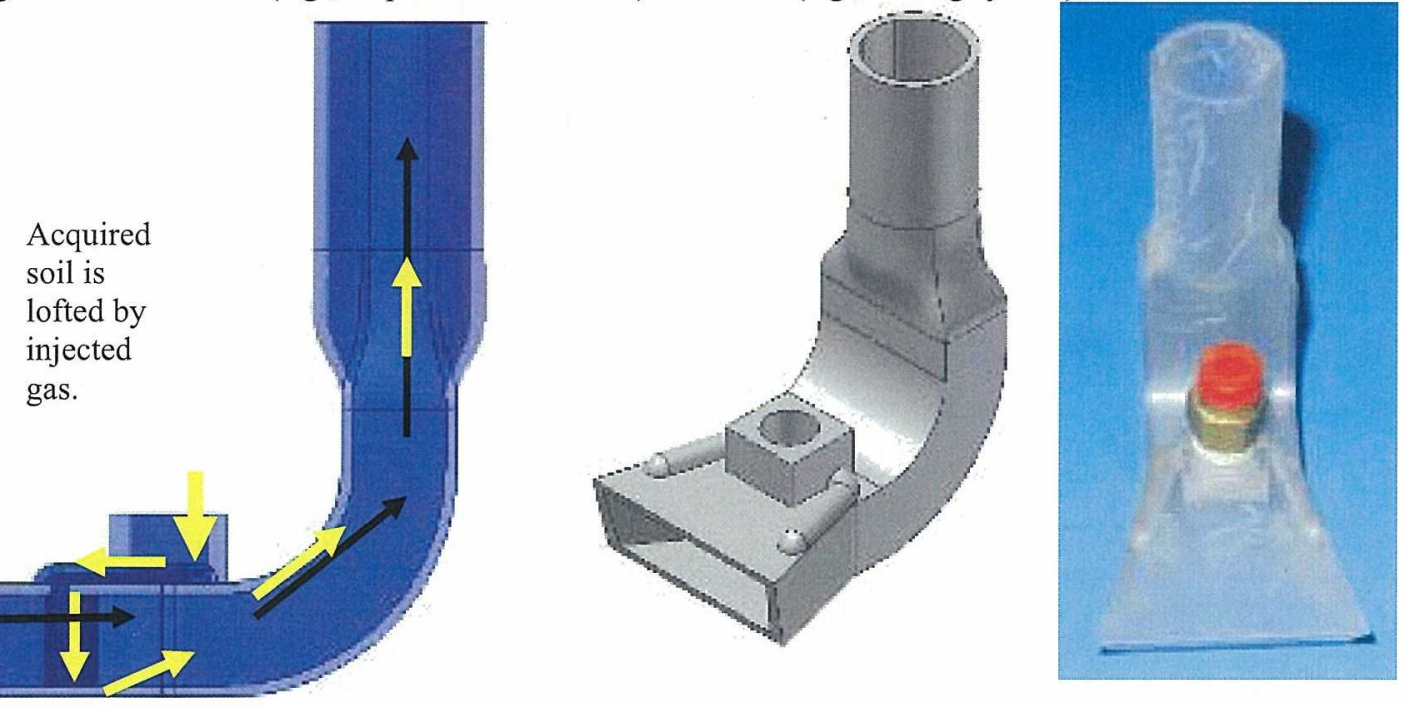

Figure 1. Various concepts of pneumatic mining nozzles. Yellow arrows show the path of gas, while black arrows show the soil path. As the gas enters the main chamber (bottom arrow), it lofts the acquired soil up the tube.

The pneumatic regolith mining system is akin to a terrestrial vacuum cleaner in that gas momentum is used to move the solid particles into a bin. The difference is that in terrestrial systems (e.g., conventional vacuum cleaners), the blower is used create a vacuum on the back-end (bin side), and air from the outside is sucked in. On the Moon, there is no air and, in turn conventional blower-type systems will not work. However, compressed gas can be delivered at the nozzle itself, to "push" the acquired soil up through the tubing and into the storage bin (the gas momentum is in fact exchanged with soil particles). The principle of operation, therefore, lies in using a puff of gas to loft the regolith acquired into a nozzle directly into a regolith bin. The nozzle is pushed into soil and dragged across the surface like a vacuum cleaner (Figure 1). A pulse of gas is delivered at the nozzle, which lofts the soil directly into a cyclone separator. A build up of regolith in front of the nozzle acts as a plug preventing gas from 
escaping from the front end. The sample falls down within the cyclone and gas escapes from the top. Gas can then be captured and recycled.

Honeybee Robotics has already demonstrated this operation in vacuum and at $1 / 6$ th gravity during reducedgravity flights. In particular, we found that the gas lifting efficiency to be in excess of 1:6000, that is with $1 \mathrm{~g}$ of gas at 5 psia we could loft $6000 \mathrm{~g}$ of JSC-1a lunar soil simulant at high velocity 7,8 .

Initially, the gas can be scavenged from a lunar lander propulsion system. This can be in the form of helium that is used to pressurize propulsion tanks or actual reserve propellant that can be burned in small thrusters and provide exhaust gas. Byproduct gasses from ISRU processing could also be used.

The 2007, the Mars Phoenix mission illustrated challenges in acquiring and delivering samples to an instrument. The soil very often was spilled around an instrument inlet and in some instances very little managed to get into the instrument itself. A pneumatic system acquires and transfers soil directly to an inlet port of an instrument or ISRU plant and thus mitigates problems related to sample transfer that Phoenix had (Table 1).

Table 1. Pros and cons for the conventional scoop and pneumatic scoop approach.

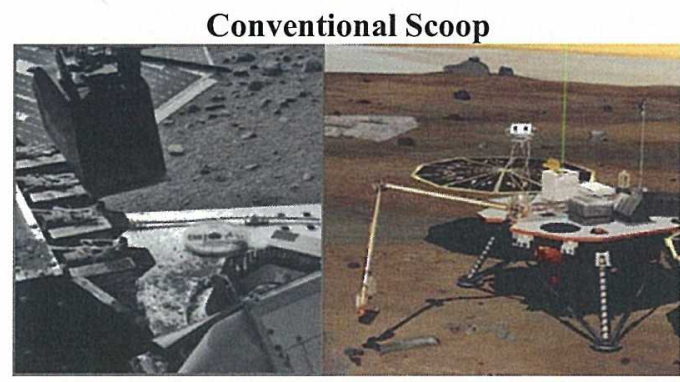

Pros

- Robust

- Can acquire larger pebbles

- Can be used as a "bulldozer" for digging trenches

Cons

- Needs 5 DOF arm

- No natural sorting, need a sieve

- Soil deposition very inaccurate

- Requires 4-movements: acquisition, move over inlet, dump, move to the surface.

- Cross contamination is an issue

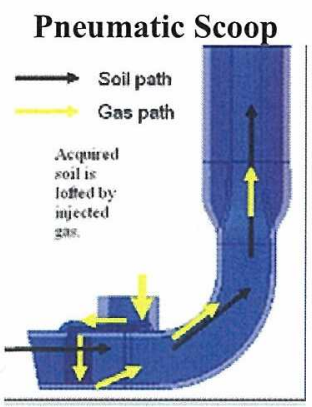

- Moves soil directly to an instrument

- Size sorting possible

- Works with 3-DOF arm

- Can use a separate blade for 'bulldozing'

- Can "clean itself" using gas and prevent cross contamination

- Needs gas (either helium from propulsion system or dedicated gas cylinder)

- Needs dedicated transfer hose

\section{B. Application of the Pneumatic Regolith Excavation Technology: Lander}

An example of utilizing pneumatic sampling system from a lander platform is shown in Figure 29. The system consists of a 3 Degree of Freedom (DOF) robotic arm with an integrated pneumatic nozzle at the end. The regolith transfer hose connects the nozzle to a cyclone separator above an ISRU plant. The arm drags the nozzle across the surface. As regolith is pushed into the nozzle, a puff of gas lofts it up and into a cyclone separator where solids drop to the bottom (ISRU plant) and gas is piped into a recycling station.

The pneumatic system uses helium from a lander's propulsion system tanks to loft soil directly into an ISRU plant. Thus, there is no need for the robotic arm to move back and forth between the lander deck and the surface ("dig - move over the bin - dump - move back to the surface" vs. "dig — send a puff of gas - move to a new digging location"), which not only saves time and energy but also reduces a number of required actuators from 5 to 3-4 (and the mission cost by $\sim \$ 2-3 \mathrm{M})$. Note the compressed $(\sim 1000 \mathrm{psi})$ helium gas is normally vented after touch down but instead can be used efficiently as a working fluid.

Another advantage of using a pneumatic transfer system is that the sample is moved directly into an ISRU plant inlet. The positioning accuracy of a scoop at the end of robotic arms is not very good. In fact, the scoop on the Mars Phoenix dumped the soil all over the lander deck while trying to discharging it over the instrument inlet port (Table 1). 


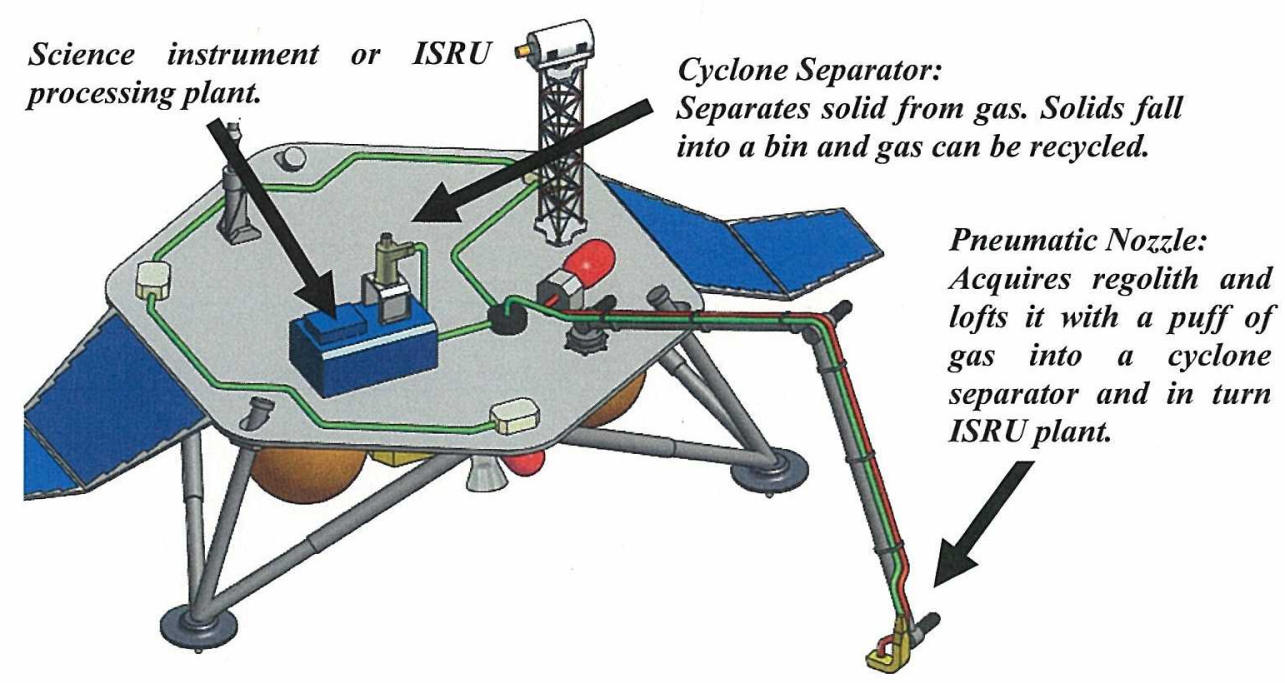

Figure 2. Future Lunar Precursor lander missions could benefit from using pneumatic sampling systems.

\section{Application of the Pneumatic Regolith Excavation Technology: Rover}

To demonstrate the operation of the pneumatic mining system off the mobile platform, the system was scaled down and integrated onto the NASA Ames K10-mini robotic platform (Figure 3). This illustrates the operation of the system from micro-rovers, which could potentially fly to the Moon on the technology precursor missions. The mining system consisted of a 1) mining nozzle, 2) delivery/mining tube, 3) cyclone (for separating solids from gas stream), 4) pneumatic delivery system (gas canister, valves), and 5) a mobile platform itself. The system was placed inside a large $(11 \times 3 \times 3 \mathrm{ft}$.) vacuum chamber filled with GRC-1 lunar soil simulant. The rover, remotely controlled from outside of the chamber, was then driven across the surface while mining the regolith directly into a soil bin10.

During a single test, the test platform traversed a full distance of the 10- $\mathrm{ft}$ tray twice (back and forth), that is, 20 $\mathrm{ft}$ total. During each traverse, 10 puffs of $\mathrm{N}_{2}$ gas at 12 psia were used to mine GRC-1 soil. The total mass of gas used during a single test was $0.5 \mathrm{~g}$ and the mass of soil mined was 300 grams. Thus, the test results showed that the mining efficiency was in the range of 1:600 (that is, with $1 \mathrm{~g}$ of gas $600 \mathrm{~g}$ of soil was excavated). The system was not optimized, though, and an order-of-magnitude improvement in excavation efficient is possible.
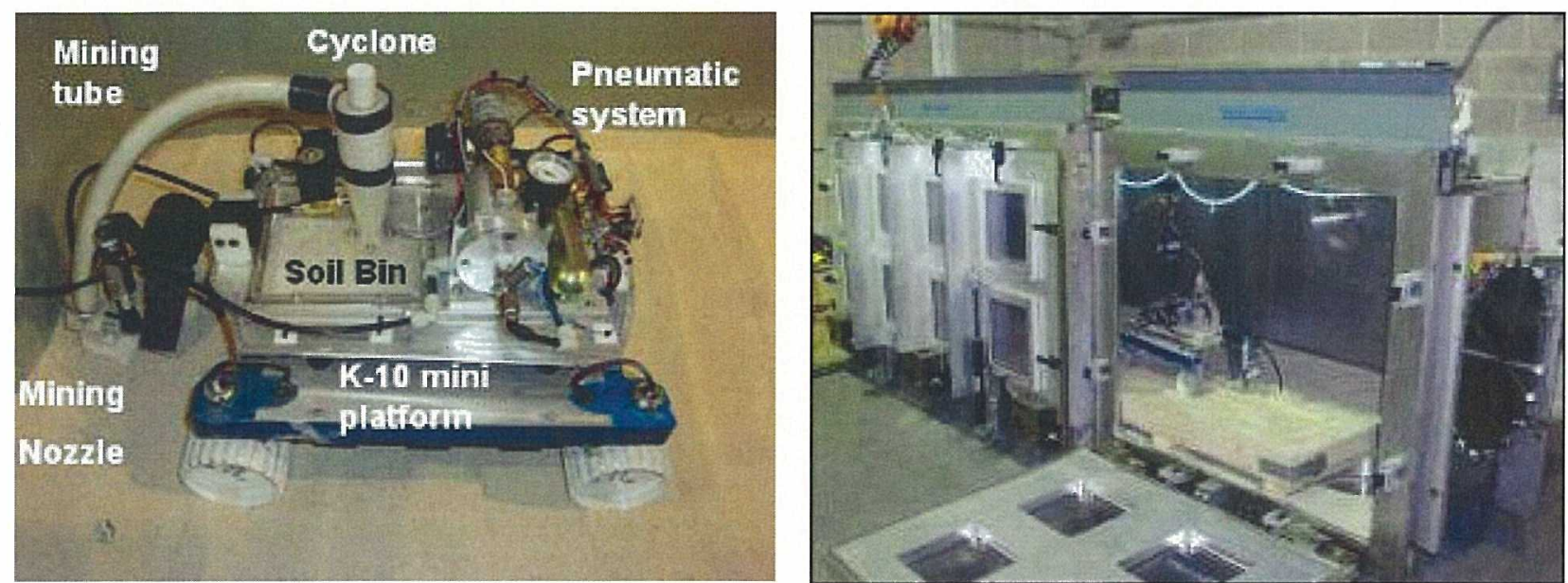

Figure 3. (left) Components of the pneumatic mining system; (right) Mining system being tested in GRC-1 lunar soil simulant, and in 11-ft-long vacuum chamber. 


\section{Application of the Pneumatic Regolith Excavation Technology: ISRU Feed System}

The principal requirement for the pneumatic regolith feed system is to lift lunar regolith from a hopper at ground level to the ISRU reactor (e.g., Carbothermal Reactor's input hopper) at a height of approximately 60 inches or more. There are a number of ways to achieve this including some kind of a bucket ladder system or an auger. However, these are mechanical systems prone to breakage, especially when used in highly abrasive lunar regolith. A more robust system is based on pneumatics. We built a pneumatic feed system, as described in Figure 4, for Orbitec's Carbothermal reactor and successfully demonstrated it during the Mauna Kea Lunar Analog field campaign in the beginning of 2010 .
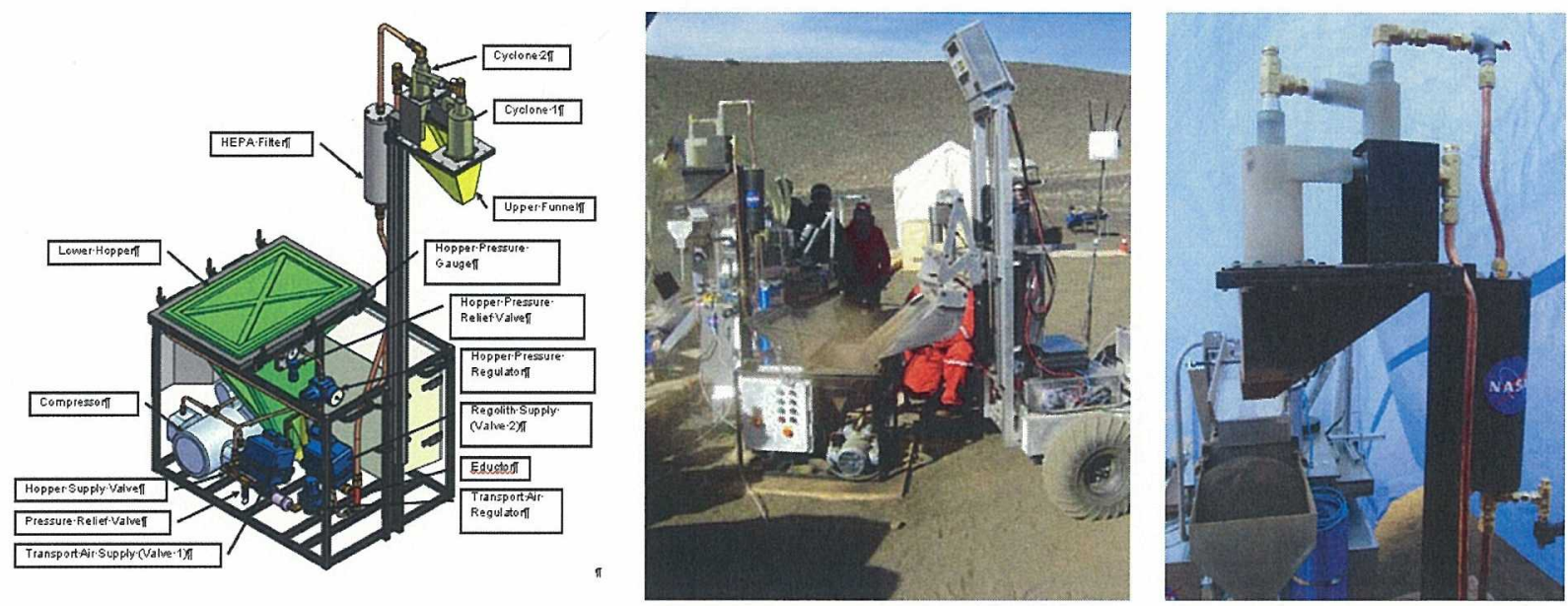

Figure 4 (left) Components of the Pneumatic Lift System; (center) Pneumatic Regolith Feed System Receiving Tephra from an Excavation Rover; (right) Successfully transferred Tephra in the Carbothermal Reactor's Input Hopper.

\section{Technology Commercialization}

Primary seed funding for developing the Honeybee Robotics regolith excavator and conveyor system originated from the Small Business Innovation Research (SBIR) program. The 2.5-billion-dollar annual investment in the program (across all participating government agencies) is designed to assist small businesses (fewer than 500 employees) in developing highly innovative technologies of value to the federal government and society. Honeybee Robotics has received funding through all three phases of the program:

- Phase I-Feasibility Study ( $\$ 100 \mathrm{~K}) 6-12$ month effort

- $\quad$ Phase II-Research (\$600K) 1-2 year effort

- Phase III-Commercialization (indirect funding, not from SBIR funding pool)

Phase III funding was provided through NASA Kennedy Space Center's Surface Systems Office, Engineering Directorate who saw the value of the technology for potential use on the lunar and Mars surfaces.

The Regolith Extractor \& Conveyor technology is a TRL-5 on the NASA TRL 1-9 scale, i.e., it has been validated in a relevant environment. A prototype of the technology was demonstrated in Hawai'i in February of 2010.

Advancing the technology from concept (TRL-1) to being fully demonstrated in the finished application (TRL-9) can be a considerable challenge. Completion of a Phase I feasibility study will typically bring the technology to a TRL 1-3 proof-of-concept level. Honeybee Robotics was awarded a full Phase II research contract resulting in raising the level to TRL-5. KSC provided Phase III funding via the Innovative Partnerships (IPP) program, to build a prototype and demonstrate the excavator and conveyor system during the NASA ISRU field campaign on Mauna Kea, HI, USA.

One of the greatest challenges for an immature technology is to secure the required funding and user support to collaborate in an applied research project. This is essential to span the "valley-of-death" between basic research and commercialization. In this particular case, NASA realizes the value of the technology and potential use on the Moon, Mars, and other space exploration destinations. Identifying more commercial applications can often be the difference between the successful deployment of a technology and a failure to exit the research stage. The team investigated construction industry organizations and felt Caterpillar would be a very valuable partner. Initial contact 
has been made with Caterpillar's Automation Electronics \& Controls Division. At the writing of this paper, the division manager has indicated interest in having some further discussions. A telecon will be held shortly to discuss potential partnership opportunities.

As NASA moves forward with the objective of integrating more commercial entities into the agencies technology road mapping process, greater attention and possibly expertise will be required to build value added partnerships.

Potential lunar missions for Honeybee Robotics/NASA technology developed through SBIR and Innovative Partnerships Program (IPP) programs were made possible despite the many challenges the group faced during the project. Two teams, Astrobotic and Earthrise Space, Inc. (Omega Envoy), surfaced to the top for potential partnership and both teams demonstrated an eagerness to host pneumatic acquisition and transfer system as payload on their future missions.

\section{Commercial Partnerships}

During the ESMD project, our intern team examined the current status of the Honeybee Robotics technology and identified two organizations interested in possibly teaming to integrate the technology as a payload into their Google Lunar X Prize lander. Non-disclosure negotiations are currently underway between Honeybee Robotics and two X Prize teams, Astrobiotic and Omega Envoy. Additionally, following a review of other potential corporate collaborators, Caterpillar Corporation was contacted as a potential partner for Honeybee in this or other potential projects. Formal discussions are expected to occur between Caterpillar, NASA Kennedy Space Center, and Honeybee Robotics.

Challenges associated with obtaining responses from an array of international X-Prize teams and several teams who elected to withdraw from the competition due to a lack of funding, quickly reduced the field of candidates. Concerns by the teams relative to supplying what they considered to be proprietary payload requirements resulted in a number of delays.

Understanding the technology integrators' and/or technology users' needs is the first step in assessing the value of a technology. Creating an assessment of the current status of a technology is an important baseline step to assess the gap that must be overcome in order to effectively integrate the technology into a finished product. In each of the matches that surfaced during this project, it appeared Honeybee Robotics' technology could fit within the parameters established by the integrators. A very valuable advantage for Honeybee is that, based upon considerable expertise and knowledge in the field of use, they can modify their core technologies to meet a variety of specifications.

Future steps needed to be taken for Honeybee Robotics to transition their pneumatic regolith excavation and sampling technology from a TRL-5 to a TRL-9. The main objective of the project was to identify a suitable company that will be sending a lander or rover to the Moon and convince them to integrate Honeybee Robotics' payload. Both teams that surfaced during the project, Astrobotic Technology and Omega Envoy, appear to be strong contenders in providing Honeybee Robotics opportunities for transportation to the lunar surface. Adding Caterpillar as another member of the team could provide considerable technical and financial resources to lead to a successful lunar project. The new direction of NASA encourages private sector involvement in the space industry. This paper highlights the possibility of Honeybee Robotics successfully partnering with the private sector to design, build, and demonstrate a mission critical technology

\section{A. Astrobotic Technology, Inc.}

Astrobotic Technology Inc. ${ }^{11}$, a spin-off from Carnegie Mellon University, is developing a series of surface robotic missions to the moon (Table 2). They will deliver more than $100 \mathrm{~kg}(240 \mathrm{lbs})$ per expedition for space agencies and corporations and beam 3D imagery to billions of people on Earth.

Destinations for early missions include Apollo sites, Surveyor 6, very near the "zero zero" coordinates at the center of the Moon's near side, and one of the newly discovered "skylights" that are mysterious holes in the surface that may lead down to volcanic caves.

These destinations are near the Moon's equator, where daytime temperatures exceed $100^{\circ} \mathrm{C}$. The robots beat this tremendous heat with an innovative asymmetric design: a substantial radiator dumps heat to black sky from the rover's shadowed side. All solar panels are on the other side and the rover always orients them to face the Sun. By reversing its camera head, it can travel east or west while keeping its solar panels Sunward, and it can move north and south by tacking like a sailboat while gaining partial sunpower. 
Table 2: Payload Specification from Astrobotic

\begin{tabular}{|l|l|}
\hline Payload Specification Questions & \multicolumn{1}{|c|}{ Astrobotic } \\
\hline Payload capacity $(\mathrm{kg})$ & $103 \mathrm{~kg}$ overall, of which $20 \mathrm{~kg}$ could be on the rover \\
\hline Payload volume ( $\left.\mathrm{m}^{3}\right)$ & TBD. The rover volume is on the order of $0.3 \mathrm{~m}^{3}$. \\
\hline Average power $(\mathrm{W})$ & TBD. The rover will have $30 \mathrm{~W}$ peak and $5 \mathrm{~W}$ continuous \\
\hline Max power (W) & TBD \\
\hline $\begin{array}{l}\text { Energy source (primary batteries, } \\
\text { solar, etc.) }\end{array}$ & $\begin{array}{l}120 \text { watts of solar power is the baseline for the rover, with a 273 Whr secondary } \\
\text { battery }\end{array}$ \\
\hline Expected mission life & $\begin{array}{l}\text { Land two days after local dawn, which gives } 12 \text { days until sundown. Currently } \\
\text { testing components to find those that can survive the night cryo cold. }\end{array}$ \\
\hline Deployment systems & $\begin{array}{l}\text { TBD. Unsure of what payloads will receive funding to buy a ride; it is possible } \\
\text { some could share in tailored deployment mechanisms. No deployment system } \\
\text { will be baselined now. }\end{array}$ \\
\hline $\begin{array}{l}\text { On-Board cameras } \\
\text { and one telephoto zoom lens with a FOV of } 5 \text { to } 40 \text { degrees. Lander may or } \\
\text { may not have cameras. }\end{array}$ \\
\hline $\begin{array}{l}\text { Max horizontal velocity during } \\
\text { landing }\end{array}$ & N/A \\
\hline $\begin{array}{l}\text { Max vertical velocity during } \\
\text { landing }\end{array}$ & $\begin{array}{l}\text { The final approach is planned to be a straight down elevator descent. Engines } \\
\text { will cut off approximately a meter above the surface. Expect the landing shocks } \\
\text { and loads to be much less than gear will experience at launch. }\end{array}$ \\
\hline $\begin{array}{l}\text { Mass and pressure of helium } \\
\text { after touch down }\end{array}$ & $\begin{array}{l}\text { None. Plan to have a GOX/methane system at 4500 psi that does not use a } \\
\text { helium pressurant. Possible residuals. }\end{array}$ \\
\hline Cost & A \$250,000 payload integration fee, in addition to the per-pound delivery cost. \\
\hline Payload integration time & It will depend on the complexity of the payload. \\
\hline
\end{tabular}

\section{B. Omega Envoy Company Information}

Earthrise Space, Inc. is a not-for-profit organization that was founded by a group of students and professionals in Central Florida with the common goal of advancing private and commercial space exploration.

The current mission for Earthrise Space is the Omega Envoy Project ${ }^{12}$. This mission consists of building a rover to be sent to the moon to win the 30 million dollar Google Lunar X PRIZE. Students and industry professionals are working together on the design of a lunar lander and a lunar rover. The lunar lander technology being developed will allow for various lunar missions that will cost orders of magnitude less than ever done before. The technology being developed by Earthrise Space for the Omega Envoy Project is focused at creating the first commercial lunar services. After proving these technologies with the Google Lunar X PRIZE, Earthrise Space will begin to provide affordable transport services to the moon. Using a universal payload system being developed the lunar services will be open to all areas of interest.

\section{Conclusion}

In this paper we presented a summary of commercialization study. The study focused on integrating a pneumatic regolith acquisition and transfer technology, developed through NASA SBIR and IPP programs, into potential commercial lunar landers.

The study involved contacting multiple commercial lunar lander teams to learn about their capabilities and interest in integrating such a system on their future landers. We learned that the commercialization of space technologies onto fledgling space company platforms is very difficult due to the large nature of unknowns and the lack of a known customer. Investors are hard to find due to the risky nature of the business plan, and the lack of a known market.

Many X-Prize competitors were either operating under a shroud of secrecy or unable to dedicate time and resources to evaluating a novel technology that was not a core part of their business plan. If a market existed or an "anchor tenant" such as NASA declared a commitment to lunar regolith mining and ISRU, then these new commercial entities and existing Fortune 500 companies like Caterpillar would be more interested in adopting new technologies to meet the customer's needs. The "valley of death" was encountered during the search for potential pneumatic excavation technology adopters, and it is evident that unless a true demand for regolith excavation 
emerges, then it will be difficult to commercialize this technology. The only obvious customer at this point is NASA and other international space agencies, who are willing to invest public funds into space research for the advancement of science and human knowledge.

\section{Acknowledgments}

The authors would like to thank the Penn State Earth and Minerals Science Department and the Pennsylvania Space Grant Consortium for their financial support of this project, as well as the NASA TecFusion program, Honeybee Robotics, and the NASA Kennedy Space Center for their support and guidance throughout our research. We would also like to thank Astrobotic Technology Inc. and Omega Envoy Company for their assistance.

\section{References}

1 http://www.cnn.com/2010/POLITICS/04/15/obama.space/index.html

2 Google Lunar X Prize website http://www.googlelunarxprize.org/

3 Mueller, R. P. and R. H. King, "Trade Study of Excavation Tools and Equipment for Lunar Outpost Development and ISRU," AIP Conf. Proc. 969, 237-244, 2008

4 2. Ivan Townsend, Robert P. Mueller, James Mantovani, Kris Zacny, Jack Craft, Performance of a Pneumatic Regolith Feed System for and In Situ Resource Utilization Production Plant in a Mauna Kea, Hawaii Analog Field Test, Aerospace Mechanisms Symposium, Orlando, FL, May 12-14, 2010

5 Sanders, G.; Larson, W., "NASA In-Situ Resource Utilization (ISRU) Development \& Field Testing," Presentation to " Hawaii's Aerospace Industry: The Next Frontier", Honolulu, The Hawaii State Capital Auditorium, August 21, 2008

6 Schrunk, David G., Sharpe, B.L., Cooper, B.L., and Thangavelu, M. (1999). "The Moon: Resources, Future Development and Colonization," Wiley-Praxis, New York.

7 Zacny, K., G. Mungas, C. Mungas, D. Fisher, and M. Hedlund, Pneumatic Excavator and Regolith Transport System for Lunar ISRU and Construction, Paper No: AIAA-2008-7824 and Presentation, AIAA SPACE 2008 Conference \& Exposition, 9 11 Sep 2008, San Diego Convention Center, San Diego, California

8 K. Zacny, R. Mueller, G. Galloway, J. Craft, G. Mungas, M. Hedlund, and P. Fink, Novel Approaches to Drilling and Excavation on the Moon, AIAA-2009-6431, Space 2009.

9 K. Zacny, D. McKay, R. Mueller, P. Chu, J. Craft, and G. Mungas, Novel Method of Regolith Sample Return from Extraterrestrial Body using a Puff of Gas. IEEEAC\#1083 (2010).

10 IEEE Spectrum, 2009: http://spectrum.iee.org/video/aerospace/robotic-exploration/lunar-vacuum-cleaner

$11 \mathrm{http}: / /$ astrobotic.net/

$12 \mathrm{http} / /$ www.omegaenvoy.org/home.html 